\begin{tabular}{ccc}
\hline International Journal of Current Research in \\
Biosciences and Plant Biology \\
\hline EXCELLENT \\
PUBLISHERS
\end{tabular}

\title{
Elicitor Application Influences the Phytochemical Profile of Salacia reticulata with the Formation of New Novel Metabolites of Medicinal Value
}

\author{
D. Ramakrishna, A. T. Shashank, S. Kiran, K. M. Kumar \\ and G. A. Ravishankar*
}

Dr. C. D. Sagar Centre for Life Sciences, Biotechnology Department, Dayananda Sagar College of Engineering (Visvesvaraya Technological University), Dayananda Sagar Institutions, Kumaraswamy Layout, Bengaluru-560 078, India

*Corresponding author.

\begin{tabular}{|c|c|}
\hline Art & ABS \\
\hline & \multirow{4}{*}{$\begin{array}{l}\text { Salacia reticulata which is a well known plant for antidiabetic properties were subject to } \\
\text { elicitor application. The field grown plants were sprayed with aqueous extracts of } 2 \% \\
\text { Aspergillus niger mycelium as biotic elicitor and } 0.2 \mathrm{mM} \text { salicylic acid as abiotic elicitor. } \\
\text { Elicitation of phenolics and flavonoids were marginal in both the treatments. } \\
\text { Formation of seven new compounds in biotic elicitor treatment and eight new } \\
\text { compounds in abiotic elicitor treatment was evident from GCMS studies. Significantly } \\
\text { Ala-Gly, Trimethylsilyl Ester; Cyclotrisiloxane, Hexamethyl and Eicosanoic Acid, 2,3- } \\
\text { Bis[(Trimethylsilyl) Oxy] Propyl Ester were the new compounds found in both the } \\
\text { elicitor treatments. Cyclotrisiloxane, Hexamethyl- is a known molecule with } \\
\text { Antioxidant, Antiasthmatics and Antogonositic effects. Interestingly, Benzene } \\
\text { acetonitrile, Alpha.-(.Beta.-D-Glucopyranosyloxy)-,(R)-, which is a potent anticancer } \\
\text { agent and Antioxidant,was found only upon biotic elicitor treatment. Thus this study } \\
\text { has led to the finding of new molecules in Salacia with potent novel medicinal } \\
\text { properties. }\end{array}$} \\
\hline $\begin{array}{l}\text { Date of Publicatio } \\
\text { 06 January } 2018\end{array}$ & \\
\hline $\mathbf{K e}$ & \\
\hline $\begin{array}{l}\text { Flavonoids } \\
\text { Medicinal plant } \\
\text { Phenolics } \\
\text { Salacia reticulata } \\
\text { Secondary metabolites }\end{array}$ & \\
\hline
\end{tabular}

\section{Introduction}

Salacia reticulata belongs to the family Celastraceae. Salacia species are commonly known as saptacharka or saptarangi in Sanskrit, and native of Asia and Africa continent used as a herbal drug to treat many diseases (Sujana et al., 2015). Salacia species contain unique phytochemicals like salcinol, Kotanol (Hiromi and Sei Ozaki, 2008), Mangiferin (Jaykumar et al., 2015) which are of pharmaceutical value in the treatment of many ailments like diabetes (Jeyakodi et al., 2016), kidney disorder, anti cholesterolemia (Singh et al., 2015), rheumatism, asthma (Romero-Pérez et al., 2016) and cancer (Musini et al., 2015). 
Elicitors are the signal molecules when applied to plants induce the synthesis of secondary metabolites and offers protections from pathogens (Manivannan et al., 2016). Elicitor are of two types, biotic (biological substance viz., metabolites, proteins, carbohydrates obtain from microbes, for example: Yeast, Fungal spores, mycelial cell wall) and abiotic (chemicals like salicyclic acid, jasmonic acid, abscisic acid, etc) (Giridhar and Parimalan, 2010; Saini et al., 2013; Ramakrishna and Ravishankar, 2011).

Ali et al. (2016) showed that foliar spray of methyl jasmonate as abiotic elictor to potato plant enhanced the secondary metabolites like phenolics, flavonoids and anthocyanins. These molecules proved to be good antioxidants with anticancer activity. Patade et al. (2016) reported that campesterol content in the cell suspension of Blumea lacera enhanced when cells were treated with salicyclic acid and extracts of mycelia of Aspergillus niger. Thiruvengadam et al. (2016) showed isofavone enhancement in soybean plant upon elicitor treatment.

In view of the importance of Salacia for the treatment of various ailments, it is of interest to enhance the potency of the extracts through augmentation of the secondary metabolites of importance. Moreover the expression of the novel molecules in Salacia would add value to this herb for finding newer applications of medicinal value. Hence we embarked up on the study to evaluate the effect of biotic and abiotic elicitor on Salacia species .The study involved the application of elicitor to the plant and evaluation of phytochemical changes upon treatments, also tracking the formation of new molecules through GC MS analysis for enhanced utility of the plant for medicinal value.

\section{Materials and methods}

Plants for the studies: Salacia reticulata plants were obtained from Government Ayurvedic college herbal garden Bangaluru, and maintain in the DSI Campus at Bangaluru, India. The plants were grown in the pot in green house.
Preparation and application of elicitors: Biotic elicitors were prepared according to Giridhar and Parimalan (2010), using fungal mycelium of Aspergillus niger. Fresh cultures of A. niger were grown on potato dextrose agar (HiMedia, Mumbai) slants and incubated for 7 days at $37{ }^{\circ} \mathrm{C}$. The spores of the respective fungi were used to prepare a spore suspension in $0.1 \%$ sodium lauryl sulfate $(\mathrm{w} / \mathrm{v})$ and diluted with sterile distilled water under sterile conditions to obtain a spore density of $\sim 2.5 \times 100$ spores $\mathrm{mL}^{-1}$. Later the same was inoculated into $150 \mathrm{~mL}$ Erlenmeyer conical flasks containing $40 \mathrm{~mL}$ of potato dextrose agar and the cultures were incubated in the dark for 10 days. After incubation, fully grown mycelia cultures were autoclaved and the mycelium was separated from the culture broth by filtration using Whatmann no. 1 filter paper and its fresh weight was recorded. An aqueous extract of the mycelium was made by homogenizing with a mortar and pestle using neutralized sand. The extract was filtered through Whatmann no. 1 filter paper, and kept as the stock solution from which a working concentration of $2.0 \% \mathrm{w} / \mathrm{v}$ (wet weight of fungal mycelium in $100 \mathrm{~mL}$ of distilled water) were prepared in sterile water and used for the elicitation experiment. Abiotic elicitor, salicylic acid was dissolved in distilled water and made up to $0.2 \mathrm{mM}$ for the study.

The biotic (2\% w/v A. niger) and abiotic $(0.2 \mathrm{mM}$ Salicyclic acid) elicitor prepared as described above were sprayed to the plants, as a fine mist, every week up to 3 weeks in the early morning hours. Control plants received distilled water sprays. The levels were selected based on the publication of Giridhar and Parimalan (2010), who have reported effective influence of elicitors on secondary metabolite in treated plants.

Plant extract preparation: Leaves of control and treated plants of Salacia were dried in shade and powdered in a blender. Soxhlet extraction of the leaf powder of the plants, both control and treatments, was done using methanol.

Estimation of total phenolic content: Total phenolic content in the plant extract was 
determined as described by Lim and Quah (2007). Briefly $300 \mu \mathrm{L}$ of plant extracts were thoroughly mixed with $1.5 \mathrm{~mL}$ of freshly diluted FolinCiocalteu reagent, to which $1.2 \mathrm{~mL}$ of sodium carbonate solution (7.5\%) was added and the mixture was incubated for $30 \mathrm{~min}$ in dark. The absorbance was measured at $765 \mathrm{~nm}$ using Spectrophotometer (UV- VIS Spectrometer SL159 ELICO). Gallic acid (Sigma Chemical Co. USA) was used as the reference standard. The concentration of phenolic content was expressed as mg of gallic acid equivalents (GAE) per g dry weight of leaf tissue.

Determination of total flavonoid content: Total flavonoid content was measured by the method of Pallab et al. (2013). One $\mathrm{mL}$ aliquots of standard quercetin (Sigma Chemicals Co, USA) solution $(100,200,400,600,800,1000 \mu \mathrm{g} / \mathrm{mL})$ was positioned into test tubes followed by $4 \mathrm{~mL}$ of distilled water and $0.3 \mathrm{~mL}$ of $5 \%$ sodium nitrite solution. After 5 minutes, $0.3 \mathrm{~mL}$ of $10 \%$ aluminum chloride was added immediately followed by $2 \mathrm{~mL}$ of $1 \mathrm{M}$ sodium hydroxide. Finally, the reaction volume was made up to $10 \mathrm{~mL}$ with distilled water and mixed well. The absorbance of orange yellowish color product developed was measured at $510 \mathrm{~nm}$ in a spectrophotometer (UV- VIS Spectrometer SL159 ELICO). The blank was performed using distilled water. Quercetin was used as reference standard. The calibration curve was plotted using standard quercetin. The data of total flavonoids were expressed as $\mathrm{mg}$ of quercetin equivalents/ $100 \mathrm{~g}$ of dry mass of leaf tissue.

GC-MS analysis: The Clarus $680 \mathrm{GC}$ was used in the analysis employing a fused silica column, packed with Elite-5MS (5\% biphenyl 95\% dimethylpoly siloxane, $30 \mathrm{~m} \times 0.25 \mathrm{~mm}$ ID $\times$ $250 \mu \mathrm{m} \mathrm{df}$ ) and the components were separated using Helium as carrier gas at a constant flow of 1 $\mathrm{mL} / \mathrm{min}$. The injector temperature was set at $260^{\circ} \mathrm{C}$ during the chromatographic run. One $\mu \mathrm{L}$ of extract sample was injected into the instrument and the oven temperature was set as follows: $60^{\circ} \mathrm{C}(2 \mathrm{~min})$ followed by $300^{\circ} \mathrm{C}$ at the rate of $10^{\circ} \mathrm{C} \mathrm{min}{ }^{-1}$ and $300^{\circ} \mathrm{C}$, where it was held for $6 \mathrm{~min}$. The mass detector conditions were as follows: transfer line temperature $240^{\circ} \mathrm{C}$; ion source temperature $240^{\circ} \mathrm{C}$; and ionization mode electron impact at $70 \mathrm{eV}$, a scan time $0.2 \mathrm{sec}$ and scan interval of $0.1 \mathrm{sec}$. column: Elite-5MS, Dimensions: $30.0 \mathrm{~m}$, $0.25 \mathrm{mmID}, 250 \mu \mathrm{m} \mathrm{df}$; initial temperature is $60^{\circ} \mathrm{C}$ for $2 \mathrm{~min}$, ramp $10^{\circ} \mathrm{C} / \mathrm{min}$ to $300^{\circ} \mathrm{C}$, hold $6 \mathrm{~min}$, , total time is $32.00 \mathrm{~min}$, carrier gas is helium, flow ( $\mathrm{mL} / \mathrm{min})$ is 1.0 , split flow: $1 \mathrm{~mL} / \mathrm{min}$, injection volume: $1 \mu \mathrm{l}$, Scan mass range: $30 \mathrm{~m} / \mathrm{z}-600 \mathrm{~m} / \mathrm{z}$ and polarity +ve. The spectrums of the components in the range of 40 to $600 \mathrm{Da}$ were compared with the database of spectrum of known components stored in the GC-MS NIST (2008) library. The identification of bioactive compounds present in the extracts was performed by comparing the mass spectra with data from NIST library. The name, of the compound in the test materials were as curtained based on retention time.

\section{Results and discussion}

\section{Phenolics and flavonoid induction by elicitors application to Salacia}

The phenolics and flavonoids in the methanolic extract of leaves of Salacia reticulata plant in control and elicitor treatments were studied (Tables 1 and 2).

It was evident from the Table 1 that the phenolic compounds increased marginally in biotic elicitors whereas the abiotic elicitor resulted in the enhancement to nearly $50 \%$. Whereas the increase in flavonoid was marginal in abiotic treatment (Table 2) and in the biotic elicitor the level of flavonoid was lower than in control. In general, the elicitor application to Salacia plants resulted in marginal enhancement of phenolics and flavonoids which would have positive beneficial influence on medicinal property of this plant.

\section{GC-MS analyses of the constituents of Salacia}

The extracts of Salacia were subjected to GC-MS analyses in order to carryout detailed phytochemical profiling. The results are presented in Fig. 1. 
Table 1. Levels of phenolics in the elicitor treated leaf tissues of Salacia reticulata.

\begin{tabular}{lll}
\hline Sl. No. & Sample name & Content equivalent to Gallic acid $\boldsymbol{\mu g} / \mathbf{m g}$ dry weight of leaf tissue \\
\hline 1 & Control & $38.36 \pm 0.2$ \\
2 & $2 \%$ A. niger treated plant & $40.71 \pm 0.8$ \\
3 & $0.2 \mathrm{mM}$ salicylic acid treated plant & $60.08 \pm 0.2$ \\
\hline
\end{tabular}

*Control: Plant sprayed with distilled water.

Table 2. Levels of Flavonoids in the elicitor treated leaf tissues of Salacia reticulata.

\begin{tabular}{lll}
\hline Sl. No. & Sample name & Content equivalent to Quercetin $\boldsymbol{\mu g} / \mathbf{m g}$ dry weight of leaf tissue \\
\hline 1 & Control & $160.16 \pm 0.1$ \\
2 & $2 \%$ A. niger treated plant & $120.24 \pm 0.2$ \\
3 & $0.2 \mathrm{mM}$ salicylic acid treated plant & $180.89 \pm 0.8$ \\
\hline
\end{tabular}

*Control: Plant sprayed with distilled water

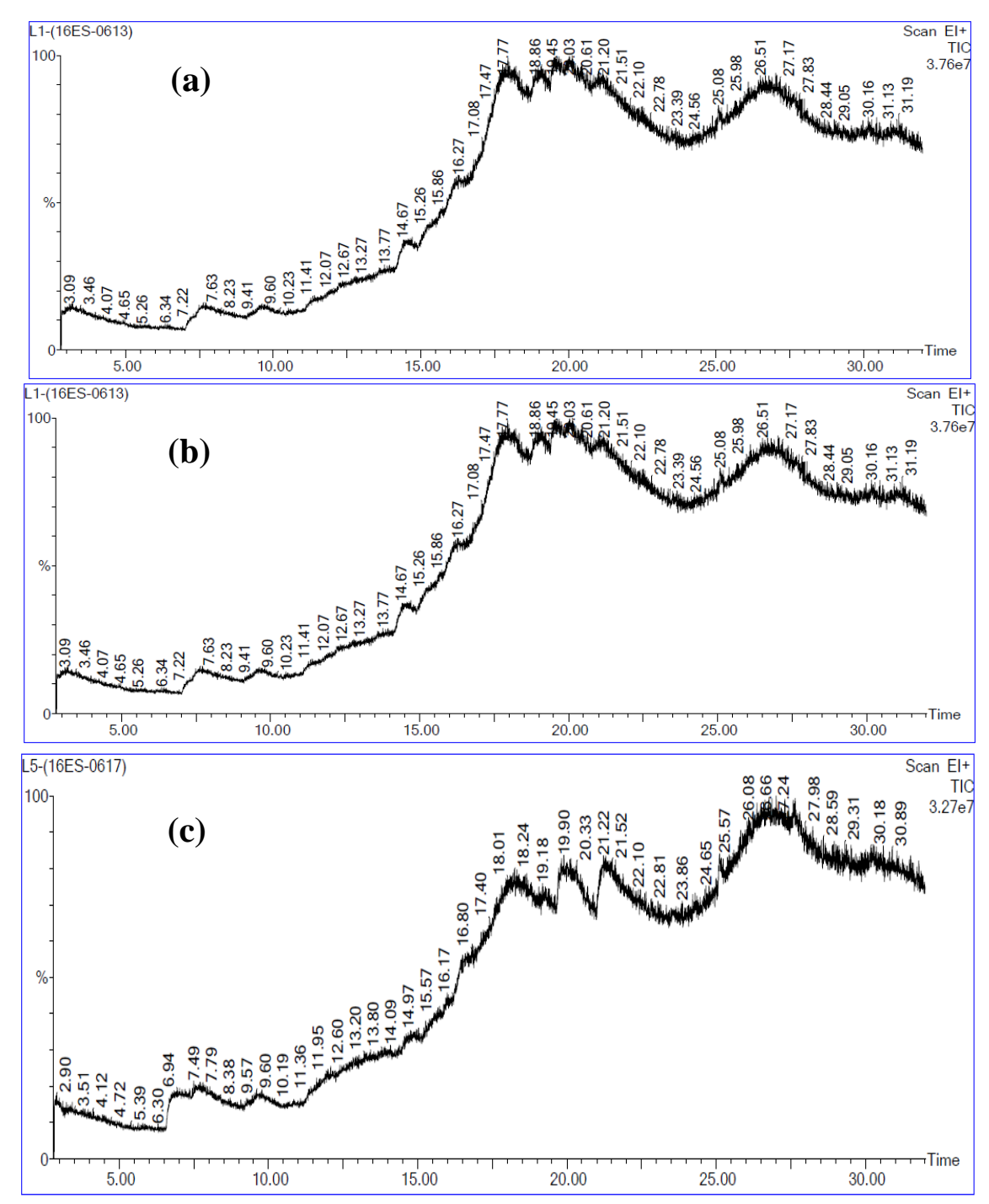

Fig. 1: Gas chromatogram of plant sprayed with distilled water (control), 2\% A. niger (Biotic elicitor) and $0.2 \mathrm{mM}$ salicylic acid (abiotic elicitor) with peak. (a) GCMS analysis showing different phytochemicals identified based on retention time of methanol extract of control plant; (b) GCMS analysis showing different phytochemicals identified based on retention time of methanol extract of 2\% A. niger (Biotic) treated plant; (c) GCMS analysis showing different phytochemicals identified based on retention time of methanol extract of $0.2 \mathrm{mM}$ salicylic acid (Abiotic) treated plant. 
The control plants showed the prevalence of 6 major phytochemicals (Table 3 ). Interestingly the treatments showed a different scenario of new and novel metabolites which were not found in control. Control plant showed the formation of (compound\#2) 1-(2-Decylaminoethoxy-2-[2-(2Trimethylsilyloxyethoxy) Ethoxy] Ethan; and (compound\#3) Butane, 1,2,3-Tris(Trimethyl siloxy)-. However these metabolites were not found in elicitor treated plants, implying that elicitor treatment also down regulated the formation of certain metabolites. Most of the publications refer to upregulation of metabolites upon elicitation (Prasad et al., 2013). However, in this study, we observed down regulation of compound \# $\mathbf{2}$ and \#3 in the elicitor treated plants. Similarly down regulation of compound \#4 (3,7,11,15,18-Pentaoxa2,19-Disilaeicosane, 2,2,19, 19-Tetramethyl-) was evident in salicylic acid treatment; similarly, compound \#5 (O-Methylisourea) and compound \#6 (Propanoic Acid, 2-Oxo-, Trimethylsilyl Ester) in $A$. niger extract treated plants (Table 3 ). The plausible explanation for down regulation could be attributed to in situ mobilization of precursors to other metabolic pathways.

It is evident from Table 3 that the treatment of Salacia plants with biotic elicitor resulted in the formation of (compound\#7 1,5,9,9-Tetramethyl -2Oxatricyclo [6.4.0.0(4,8)] Dodecane; (compound \#8) Benzeneacetonitrile, Alpha.-(.Beta.-D-Gluco pyranosyloxy)-, (R)-; (compound\#9) Trimethyl [4(1,1,3,3,-Tetramethylbutyl) Phenoxy] Silane; (compound\#10) Tetracosanoic Acid, Trimethylsilyl Ester as exclusive metabolites. Hence upregulation of certain novel pathway is evident with the formation of these new compounds not found in the control plants. The biological significance of these novel molecules will be interesting to study.

In contrast, the treatment of Salacia plants with abiotic elicitor Table 3 resulted in formation of yet other exclusive metabolites viz., C3,27-Dioxa-2,28Disilanonacosane, 2,2,4,28,28-Pentamethyl-, (compound\#14); Eicosanoic Acid, 2,3Bis[(Trimethylsilyl) Oxy] Propyl Ester (compound\#15); Undecanoic Acid, 11-Fluoro-, Trimethylsilyl Ester; (compound\#16) Decanoic Acid, 10-Fluoro-, Trimethylsilyl Ester; (compound\#17) Oleic Acid, Trimethylsilyl Ester; (compound\#18) 17-Octadecynoic Acid, Trimethylsilyl Ester. Thus the exclusive influence of biotic and abiotic elicitors in the formation several novel compounds were highly evident.

(Compound\#11) A la-Gly, Trimethylsilyl Ester; (compound\#12) Cyclotrisiloxane, Hexamethyland (compound \#13) Eicosanoic Acid, 2,3-Bis [(Trimethylsilyl) Oxy] Propyl Ester, were the three chemicals commonly found in biotic and abiotic treated plants of Salacia and not found in control plants (Table 4). Whereas, (compound\#14) 3,27Dioxa-2,28-Disilanonacosane, 2,2,4,28,28-Penta methyl-; (compound\#15). Undecanoic Acid, 11Fluoro-, Trimethylsilyl Ester; (compound\#16). Decanoic Acid, 10-Fluoro-, Trimethylsilyl Ester; (compound\#17) Oleic Acid, Trimethylsilyl Ester, were found in abiotic elicitor treatment only and not in biotic elicitor treatments or in control.

In general the GC MS profile showed 6 common compounds in control, whereas biotic elicitor showed 7 new compounds and abiotic elicitor showed 8 new compounds respectively (Table 3 ).

The PubMed website based analyses of biological activities of elicited metabolites of Salacia plants showed interesting properties (Table 4).

Evidently, (compound\#12) Cyclotrisiloxane, Hexamethyl- was a new novel compound found in both the elicitor treatment- biotic and abiotic which is supposed to be a potent Antioxidant, Antiasthmatics, Antogonositic effects, and also it is a signal molecule. Moreover, (compound\#17) Oleic Acid, Trimethylsilyl Ester found in abiotic elicitor treatment is a known antitumour compound. Benzeneacetonitrile, .Alpha.-(.Beta.-D-Gluco pyranosyloxy)-, (R)-(compound\#8) found in biotic elicitor treatment is known for anticancer and antioxidant property. Further analyses through in vitro and in vivo models would throw light on the biological activities of these molecules with respect to Salacia. 
Table 3. Comparative account of plant sprayed with distilled water (Control), $2 \%$ A. niger (Biotic) and $0.2 \mathrm{mM}$ salicylic acid (Abiotic) with GCMS chemical profiling.

\begin{tabular}{|c|c|c|c|c|c|c|}
\hline $\begin{array}{l}\text { Compound } \\
\text { number }\end{array}$ & $\begin{array}{l}\text { Molecular } \\
\text { formula }\end{array}$ & MW & $\begin{array}{l}\text { Retention } \\
\text { time }\end{array}$ & Control & $\begin{array}{l}2 \% \\
\text { A. niger }\end{array}$ & $\begin{array}{l}0.2 \mathrm{mM} \\
\text { salicylic acid }\end{array}$ \\
\hline 1 & $\mathrm{C}_{13} \mathrm{H}_{26} \mathrm{O}_{6} \mathrm{NSiB}$ & 331 & $\begin{array}{l}22.506 \\
18.005 \\
18.240 \\
18.600\end{array}$ & + & + & + \\
\hline 2 & $\mathrm{C}_{21} \mathrm{H} 4{ }_{7} \mathrm{O}_{4} \mathrm{NSi}$ & 405 & 16.269 & + & $-*$ & $-*$ \\
\hline 3 & $\mathrm{C}_{13} \mathrm{H}_{34} \mathrm{O}_{3} \mathrm{Si}_{3}$ & 320 & 20.120 & + & $-*$ & $-*$ \\
\hline 4 & $\mathrm{C}_{17} \mathrm{H}_{4} \mathrm{OO}_{5} \mathrm{Si}_{2}$ & 380 & $\begin{array}{l}17.949 \\
18.345\end{array}$ & + & + & $-*$ \\
\hline 5 & $\mathrm{C}_{2} \mathrm{H}_{6} \mathrm{ON}_{2}$ & 74 & $3.204,7.715$ & + & $-*$ & + \\
\hline 6 & $\mathrm{C}_{6} \mathrm{H}_{12} \mathrm{O}_{3} \mathrm{Si}$ & 160 & $\begin{array}{l}19.090 \\
20.000 \\
19.725\end{array}$ & + & $-*$ & + \\
\hline 7 & $\mathrm{C}_{15} \mathrm{H}_{26} \mathrm{O}$ & 222 & 24.922 & - & + & - \\
\hline 8 & $\mathrm{C}_{14} \mathrm{H}_{17} \mathrm{NO}_{6}$ & 295 & $\begin{array}{l}19.485 \\
19.600 \\
19.980\end{array}$ & - & + & - \\
\hline 9 & $\mathrm{C}_{17} \mathrm{H}_{30} \mathrm{OSI}$ & 278 & 27.438 & - & + & - \\
\hline 10 & $\mathrm{C}_{27} \mathrm{H}_{56} \mathrm{O}_{2} \mathrm{SI}$ & 440 & 20.080 & - & + & - \\
\hline 11 & $\mathrm{C}_{8} \mathrm{H}_{18} \mathrm{~N}_{2} \mathrm{O}_{3} \mathrm{SI}$ & 218 & $2.993,2.903$ & - & + & + \\
\hline 12 & $\mathrm{C}_{6} \mathrm{H}_{18} \mathrm{O}_{3} \mathrm{SI}_{3}$ & 222 & $\begin{array}{l}26.768 \\
27.578\end{array}$ & - & + & + \\
\hline 13 & $\mathrm{C}_{29} \mathrm{H}_{62} \mathrm{O}_{4} \mathrm{SI}_{2}$ & 530 & $\begin{array}{l}20.006 \\
19.895 \\
20.095 \\
21.191\end{array}$ & - & + & + \\
\hline 14 & $\mathrm{C}_{30} \mathrm{H}_{66} \mathrm{O}_{2} \mathrm{SI}_{2}$ & 514 & 19.815 & - & - & + \\
\hline 15 & $\mathrm{C}_{14} \mathrm{H}_{29} \mathrm{O}_{2} \mathrm{FSI}$ & 276 & 20.135 & - & - & + \\
\hline 16 & $\mathrm{C}_{13} \mathrm{H}_{27} \mathrm{O}_{2} \mathrm{FSI}$ & 262 & 20.326 & - & - & + \\
\hline 17 & $\mathrm{C}_{21} \mathrm{H}_{42} \mathrm{O}_{2} \mathrm{SI}$ & 354 & 21.221 & - & - & + \\
\hline 18 & $\mathrm{C}_{21} \mathrm{H}_{40} \mathrm{O}_{2} \mathrm{SI}$ & 352 & 21.296 & - & - & + \\
\hline
\end{tabular}

+ Denotes Presence; - Denotes Absence of the compound; * Down regulated in elicitor treatments only.

Compound \#; (1) Alpha.-D-Glucopyranoside, Methyl 2-(Acetylamino)- 2-Deoxy-3-O-(Trime; (2) 1-(2-Decyl aminoethoxy-2-[2-(2-Trimethylsilyloxyethoxy)Ethoxy]Ethan; (3) Butane,1,2,3-Tris(Trimethylsiloxy)-; (4) 3,7,11, 15,18-Pentaoxa-2,19-Disilaeicosane,2,2,19,19-Tetramethyl-; (5) O-Methylisourea; (6) Propanoic Acid, 2-Oxo-, Trimethylsilyl Ester; (7) 1,5,9,9-Tetramethyl-2-Oxatricyclo[6.4.0.0(4,8)] Dodecane; (8) Benzeneacetonitrile, Alpha.(.Beta.-D-Glucopyranosyloxy)-,(R)-; (9) Trimethyl [4-(1,1,3,3,-Tetramethylbutyl) Phenoxy] Silane; (10) Tetracosanoic Acid, Trimethylsilyl Ester; (11) Ala-Gly, Trimethylsilyl Ester; (12) Cyclotrisiloxane, Hexamethyl-; (13) Eicosanoic Acid, 2,3-Bis[(Trimethylsilyl) Oxy] Propyl Ester; (14) 3,27-Dioxa-2,28-Disilanonacosane, 2,2,4,28,28-Pentamethyl-; (15) Undecanoic Acid, 11-Fluoro-, Trimethylsilyl Ester; (16) Decanoic Acid, 10-Fluoro-, Trimethylsilyl Ester; (17) Oleic Acid, Trimethylsilyl Ester; (18) 17-Octadecynoic Acid, Trimethylsilyl Ester. 
Table 4. Biological property of identified Phytochemical in methanol leaf extract of Salacia reticulata plants sprayed with distilled water (Control), $2 \%$ A. niger (Biotic) and $0.2 \mathrm{mM}$ salicylic acid (Abiotic) by GC-MS with molecular weight (M.W), Formula.

\begin{tabular}{|c|c|c|}
\hline $\begin{array}{l}\text { Compound } \\
\text { no. }\end{array}$ & Compound name & Biological property \\
\hline 1 & $\begin{array}{l}\text { Alpha.-D-Glucopyranoside, Methyl 2-(Acetylamino)- 2-Deoxy- } \\
\text { 3-O-(Trime }\end{array}$ & NK \\
\hline 2 & $\begin{array}{l}\text { 1-(2-Decylaminoethoxy-2-[2-(2-Trimethylsilyloxyethoxy) } \\
\text { Ethoxy]Ethan }\end{array}$ & NK \\
\hline 3 & Butane, 1,2,3-Tris(Trimethylsiloxy)- & NK \\
\hline 4 & $\begin{array}{l}\text { 3,7,11,15,18-Pentaoxa-2,19-Disilaeicosane,2,2,19,19- } \\
\text { Tetramethyl- }\end{array}$ & NK \\
\hline 5 & O-Methylisourea & $\begin{array}{l}\text { Antifungal, Antibacterial, } \\
\text { cough suppressant, } \\
\text { Antitussitive, Mucolytic }\end{array}$ \\
\hline 6 & Propanoic Acid, 2-Oxo-, Trimethylsilyl Ester & NK \\
\hline 7 & 1,5,9,9-Tetramethyl-2-Oxatricyclo[6.4.0.0(4,8)]Dodecane & NK \\
\hline 8 & Benzeneacetonitrile,.Alpha.-(.Beta.-D-Glucopyranosyloxy)-, (R)- & Antioxidant, anticancer \\
\hline 9 & Trimethyl [4-(1,1,3,3,-Tetramethylbutyl) Phenoxy] Silane & NK \\
\hline 10 & Tetracosanoic Acid, Trimethylsilyl Ester & $\begin{array}{l}\text { Antioxidant, Antimicrobial, } \\
\text { Insecticidal activity }\end{array}$ \\
\hline 11 & Ala-Gly, Trimethylsilyl Ester & NK \\
\hline 12 & Cyclotrisiloxane, Hexamethyl- & $\begin{array}{l}\text { Antioxidant, Antiasthmatics, } \\
\text { Antogonositic, Signal molecule } \\
\text { with small MW molecule }\end{array}$ \\
\hline 13 & 3,27-Dioxa-2,28-Disilanonacosane, 2,2,4,28,28-Pentamethyl- & NK \\
\hline 14 & Eicosanoic Acid, 2,3-Bis [(Trimethylsilyl) Oxy] Propyl Ester & NK \\
\hline 15 & Undecanoic Acid, 11-Fluoro-, Trimethylsilyl Ester & NK \\
\hline 16 & Decanoic Acid, 10-Fluoro-, Trimethylsilyl Ester & NK \\
\hline 17 & Oleic Acid, Trimethylsilyl Ester & $\begin{array}{l}\text { Cancer Preventive, anti- } \\
\text { inflammmatory, } \\
\text { hypocholesterolemic }\end{array}$ \\
\hline 18 & 17-Octadecynoic Acid, Trimethylsilyl Ester & NK \\
\hline
\end{tabular}

NF-Not found in website www.http//pubchem.ncbi.nlm.nih.gov/compound.

NK-Not Known.

Thus the present study has shown the potential of elicitor application in producing novel compounds with some new biological activities which are hitherto not found in the Salacia plants. Hence the study has been useful in possibly enhancing the medicinal application of Salacia through elicitor treatment. The validation of the biological activities of Salacia with respect to the newly predicted pharmacological potential is in progress.

\section{Conflict of interest statement}

Authors declare that they have no conflict of interest.

\section{Acknowledgement}

The author, Dr. D. Ramakrishna thanks University Grants Commission, New Delhi for funding. Authors acknowledge services of GCMS Lab, Sophisticated Analytical instrumentation Facility, 
VIT, Vellore, India. The authors are grateful to Dr. Premachandra Sagar, Vice Chairman, Dayananda Sagar Institutions, Bangalore, for his generous support, encouragement and facilities.

\section{References}

Ali, G., Talei, D., Jaafar, H.Z.E., Juraimi, A.S., Mohamed, M.T. M., Puteh, A., Halim, M.R.A., 2016. Plant-growth regulators alter phytochemical constituents and pharmaceutical quality in Sweet potato (Ipomoea batatas L.). BMC Compl. Alt. Med. 16(152), 1-13.

Giridhar, P., Parimalan, R., 2010. Biotechnological perspective towards improvement of annatto color production for value addition - the influence of biotic elicitors. Asia Pac. J. Mol. Biol. Biotechnol. 18(1), 77-79.

Hiromi, O.E., Sei Ozaki, Y., 2008. Hypoglycemic effect of 13-membered ring thiocyclitol, a novel -glucosidase inhibitor from Kothala-himbutu (Salacia reticulata). Biosci. Biotechnol. Biochem. 72(7), 1962-1964.

Jaykumar, J.C., Dhanaji, M.G., Ashok, S., Suraj, D.U., 2015. Micropropagation, molecular profiling and RP-HPLC determination of mangiferin across various regeneration stages of Saptarangi (Salacia chinensis L.). Indust. Crops Prod. 76(15), 1123-1132.

Jeykodi, S., Deshpande, J., Juturu, V., 2016. Salacia extract improves postprandial glucose and insulin response: A randomized double-blind, placebo controlled, crossover study in healthy volunteers. J. Diabetes Res. 2016, 7971831.

Lim, Y. Y., Quah, E. P. L., 2007. Antioxidant properties of different cultivars of Portulaca oleracea. Food Chem. 103, 734-740.

Manivannan, A., Soundararajan, P., Park, Y.G., Jeong, B.R., 2016. Chemical elicitor-induced modulation of antioxidant metabolism and enhancement of secondary metabolite accumulation in cell suspension cultures of Scrophularia kakudensis Franch. Int. J. Mol. Sci. 17(399), 1-13.

Musini, A., Rao, J.P., Giri, A., 2015. Phytochemicals of Salacia oblonga responsible for free radical scavenging and antiproliferative activity against breast cancer cell lines (MDAMB-231). Physiol. Mol. Biol. Plants. 2(4), 583590.

Pallab, K., Tapan, B., Tapas, P., Ramen, K., 2013. Estimation of total flavonoids content (TPC) and antioxidant activities of methanolic whole plant extract of Biophytum sensitivum Linn. J. Drug Deliv. Therapeut. 3(4), 33-37.

Patade, P., Mendhulkar, V. D., Vakil, M., 2016. Campesterol elicitation in Blumea lacera (Burm.f.) DC. cell culture using salicylic acid and Aspergillus niger. Int. J. Green Herbal Chem. 5(4), 308-318.

Prasad, A., Mathur, A., Kalra, A., Gupta, M.M., Lal, R.K., Mathur, A.K., 2013. Fungal elicitormediated enhancement in growth and asiaticoside content of Centella asiatica L. shoot cultures. Plant Growth Regul. 69(3), 265273.

Ramakrishna, A., Ravishankar, G.A., 2011. Influence of abiotic stress signals on secondary metabolites in plants. Plant Signal. Behav. 6(11), 1720-1731.

Romero-Pérez, G.A., Egashira, M., Harada, Y., Tsuruta, T., Oda, Y., Ueda, F., Tsukahara, T., Tsukamoto, Y., Inoue, R., 2016. Orally administered Salacia reticulata extract reduces $\mathrm{H} 1 \mathrm{~N} 1$ Influenza clinical symptoms in murine lung tissues putatively due to enhanced natural killer cell activity. Front. Immunol. 7, 115.

Saini, R.K., Akithadevi, M.K., Giridhar, P., Ravishankar, G.A., 2013. Augmentation of major isoflavones in Glycine $\max$ L. through the elicitor-mediated approach. Acta Bot. Croatica. 72(2), 311-322.

Singh, R.G., Rathore, S.S., Wani, I.A., Usha, Agrawal, A., Dubey, G.P., 2015. Effects of Salacia oblonga on cardiovascular risk factors in chronic kidney disease patients: A prospective study. Saudi J. Kidney Dis. Transpl. 26, 61-66.

Sujana, K. A., Nagaraju, S., Narayanan, M. K. R., Anil Kumar, N., 2015. A new species of Salacia (Celastraceae) from India. Taiwania. 60(2), 9194.

Thiruvengadam, M., Baskar, V., Kim, S., Chung, I., 
2016. Effects of abscisic acid, jasmonic acid and salicyclic acid on the content of phytochemicals and their gene expression profile and biological activity in Turnip (Brassica rapa). Plant Growth Regul. 80, 377390.

\section{How to cite this article:}

Ramakrishna, D., Shashank, A.T., Kiran, S., Kumar, K.M., Ravishankar, G.A., 2018. Elicitor application influences the phytochemical profile of Salacia reticulata with the formation of new novel metabolites of medicinal value. Int. J. Curr. Res. Biosci. Plant Biol. 5(1), 35-43.

doi: https://doi.org/10.20546/ijcrbp.2018.501.005 